\title{
Machine Monitoring System
}

\author{
Karunamoorthy, Sujithra.V, Kabilan.S
}

\begin{abstract}
At present, it is hard to maintain and monitor the machine tool in industry. This paper proposed one kind of machine monitoring system using current transformer and RTC. In this scheme, C.T, P.T, ZCD continuously monitor the machine and give the status to the arduino. The arduino intimates the GSM to send the message to the owner/manager whenever the non-working timing is exceed the certain limit.

Keywords: - Current transformer, RTC, Potential transformer, ZCD, GSM .
\end{abstract}

\section{INTRODUCTION}

As entering a new era of advanced technology, each and everything is connected with each other but in the machines , the major problem is overload and underload condition due to this problem the products are delayed to reach the consumer and at the same time machine performance and efficiency also reduced due to some external factors like temperature, etc. that's why the system called machine monitoring system is proposed which is used to detect the fault in the machine due to some problems like overload, underload condition.At present, it is hard to maintain and monitor the machine tool in industry. This paper proposed one kind of machine monitoring system using current transformer and potential transformer. In this scheme, C.T, P.T, ZCD continuously monitor the machine and give the status to the arduino. The arduino intimates the GSM to send the message to owner/manager whenever the non-working timing is exceed the certain limit. As the paper is mainly focused on machine condition monitoring and it involves in the electrical arrangement to monitor and send the message to the owner . so the field of the paper is fully concerned on electrical and electronics especially based on machine and embedded system .some of the electrical components like current transformer which is used to note the current consumed by the machine . the temperature sensors also used to note the value of the temperature in the machine . the arduino is used to intimate the GSM module to send the message to the owner whenever the value exist the certain given limit. To improve the performance and efficiency of the machine using the data given by the monitoring system. To monitor the machine continuously and detect the fault like overload or underload condition. To save the time and supply the products to the customer within the time.

Revised Manuscript Received on August 14, 2019.

Dr.Karunamoorthy, Associate professor Electrical and Electronics Kumaraguru College of Technology, Coimbatore, India. (karunamoorthy.b.eee@kct.ac.in)

Sujithra.V, Electrical and Electronics Dept Kumaraguru College of Kumaraguru College of Technology Coimbatore India. (sujithra.15ee@kct.ac.in)

Kabilan.S, Electrical and Electronics Dept Kumaraguru College of Technology, Coimbatore, India. (kabilan.15ee@kct.ac.in) Technology, Coimbatore, India. (Electrical and Electronics Dept

\section{COMPONENTS DESCRIPTION}

This paper demonstrates the design of working model of the machine monitoring system. Following are the components used in this system.

\section{A) Current transformer (C.T)}

The current transformer (C.T), is the type of "instrument transformer" that is designed to produce an alternating current in its secondary winding which is proportional to the current being measured in its primary. Here, there is a use C.T to measure the consumption of current in the machine, based on current consumption able to know machine condition.

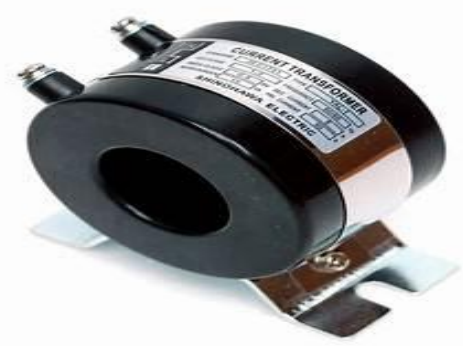

\section{FIG 1 -CURRENT TRANSFORMER}

B) Global system for mobile communication (GSM module)

GSM/GPRS module is used to establish communication between a computer and a GSM/GPRS system . GSM (Global System for Mobile communication) is an architecture used for mobile communication .It consist of GSM/GPRS modem assembled together with power supply circuit and communication interfaces.

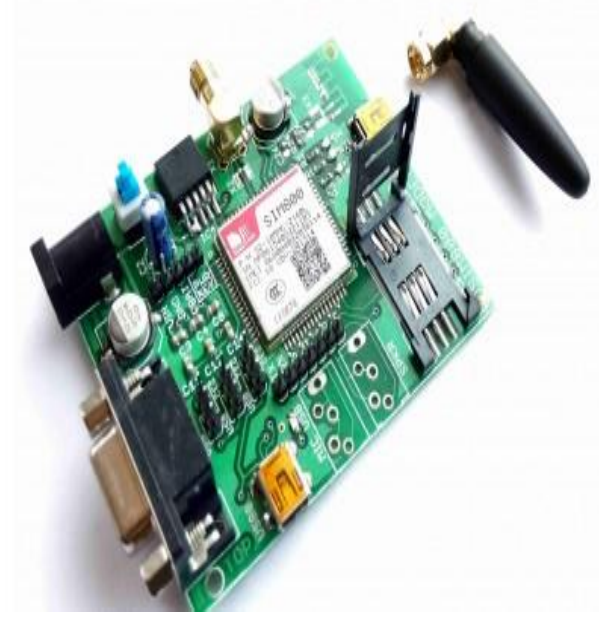

FIG -2 GSM MODULE

Published By: Blue Eyes Intelligence Engineering 


\section{MACHINE MONITORING SYSTEM}

\section{C) Potential Transformer(P.T)}

The potential transformer may be defined as an instrument transformer used for the transformation of voltage from a higher value to the lower value. This transformer step down the voltage to a safe limit value which can be easily measured by the ordinary low voltage instrument like a voltmeter, wattmeter and watt-hour meters, etc.

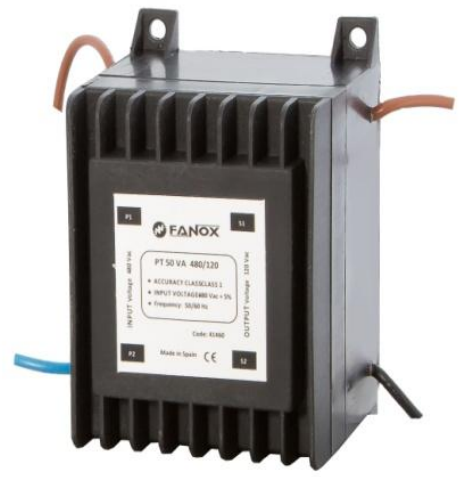

FIG -3 POTENTIAL TRANSFORMERS

\section{D) Zero crossing detector (ZCD)}

Zero crossing detector is a voltage comparator that changes the $\mathrm{o} / \mathrm{p}$ between $+\mathrm{Vsat} \&-$ Vsat when the $\mathrm{i} / \mathrm{p}$ crosses zero reference voltage. In simple words, the comparator is a basic operational amplifier used to compare two voltages simultaneously and changes the o/p according to the comparison. In the same way we can say ZCD is a comparator.

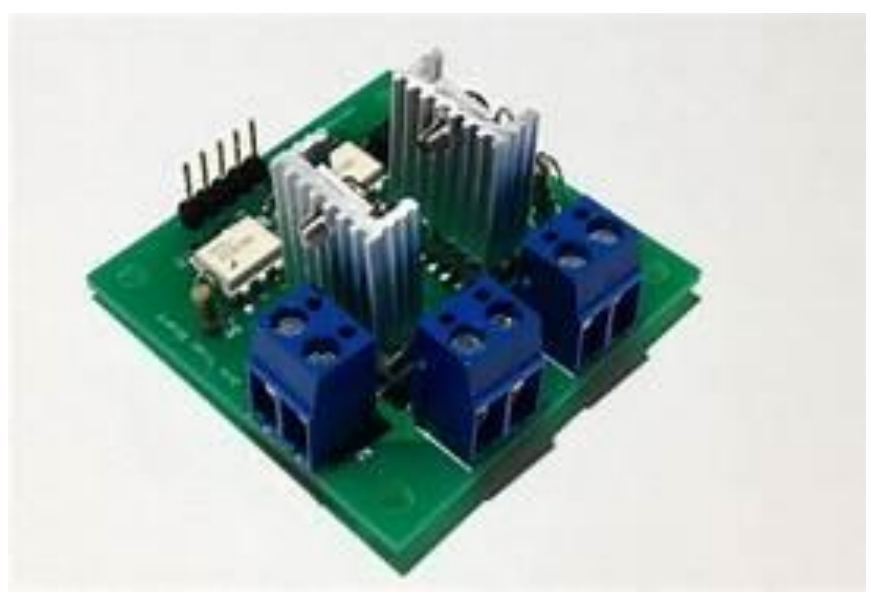

FIG -4 ZERO CROSSING DETECTOR

\section{E) Real Time Clock (RTC)}

The purpose of real time clock (RTC) is to provide precise time and date which can be used for various applications. RTC is an electronic device in the form of an integrated chip (IC) available in various packaging options. In this paper RTC is used to measure the running and the idle time of machines. By subtracting the idle and running time, the non-working condition of the machine is known .

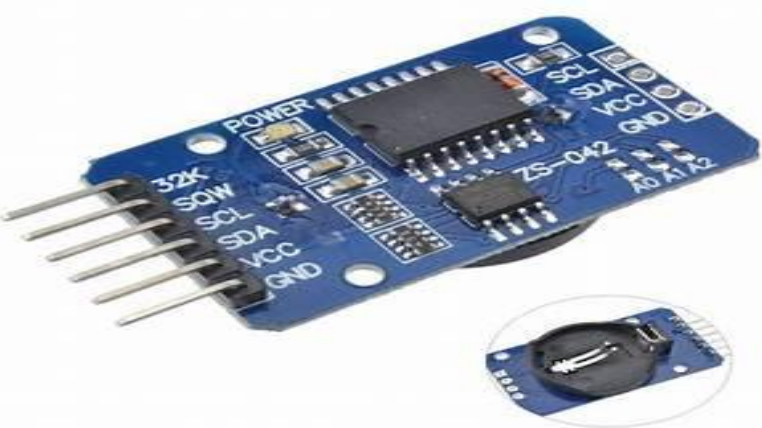

FIG -5 REAL TIME CLOCK

\section{BLOCK DIAGRAM}

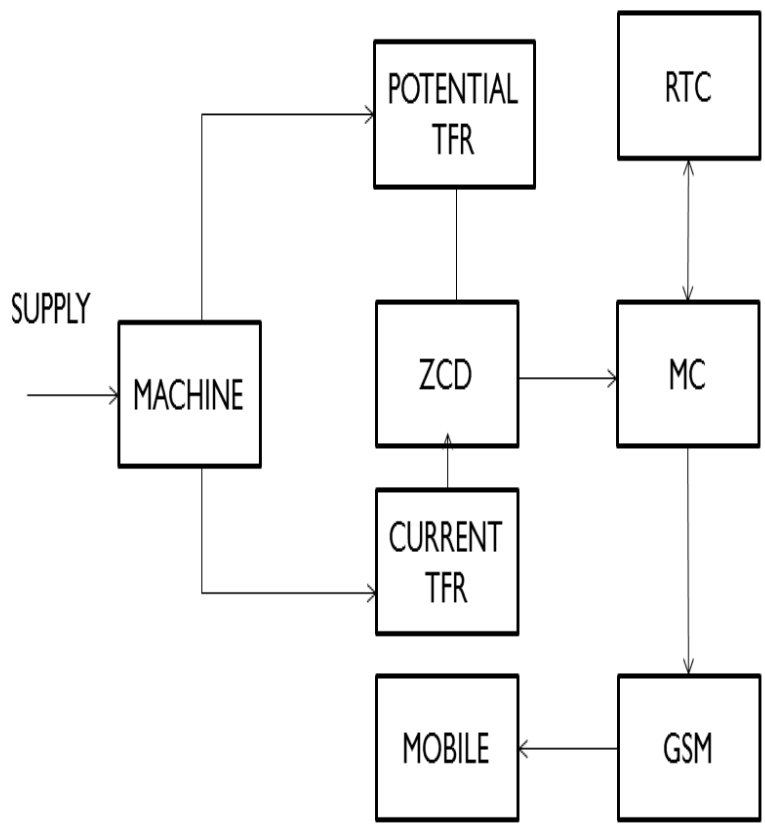

FIG -6 PROPOSED MODEL BLOCK DIAGRAM

As the paper is mainly focused on machine condition monitoring and it involves in the electrical arrangement to monitor and send the message to the owner. So the field of the paper is fully concerned on electrical and electronics especially based on machine and embedded system .some of the electrical components like current transformer which is used to note the current consumed by the machine. The arduino is used to intimate the GSM module to send the message to the owner whenever the value exist the certain given limit.

\section{FLOW CHART}




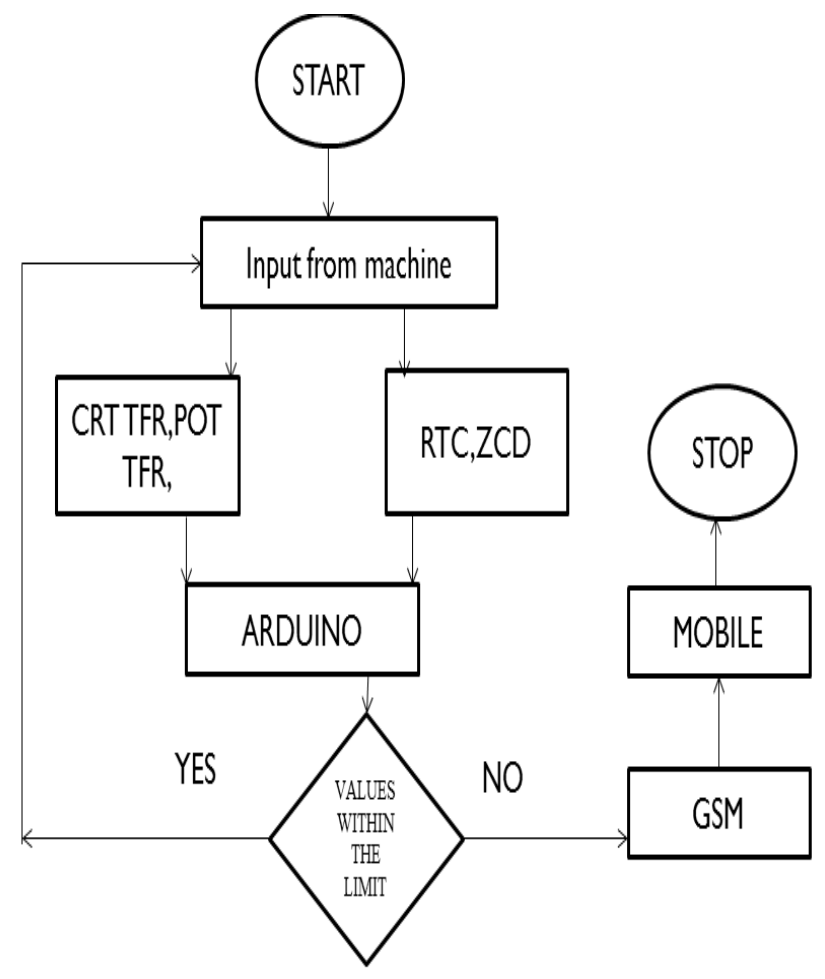

FIG -7 FLOW CHART

\section{IMPLEMENTATION OF THE SYSTEM}

When the machine is in running condition, the supply to the machine is connected to the current transformer (C.T) and potential transformer (P.T). The current transformer continuously monitors the machine and sends it to the zero crossing detectors. Then, ZCD send the signal to the micro controller. At the same time RTC send the values to the arduino. Calculate the non-working time using idle and running time. If the non-working time is exceeding the certain level, microcontroller intimates the gsm module to send the message to the owner.

\section{HARDWARE RESULTS}

In hardware, The input supply is given to the arduino using USB cable The input from the machine such as current consumed by the machine is monitored by the current transformer and potential transformer. At the same time idle and the running time also calculated by the real time clock (RTC).These inputs are given to the microcontroller to ensure the values are within the limit if the certain limit is exceed the microcontroller (Arduino) intimate the GSM module to send the message to the owner or manager about the faulty condition or non working time of the machine.

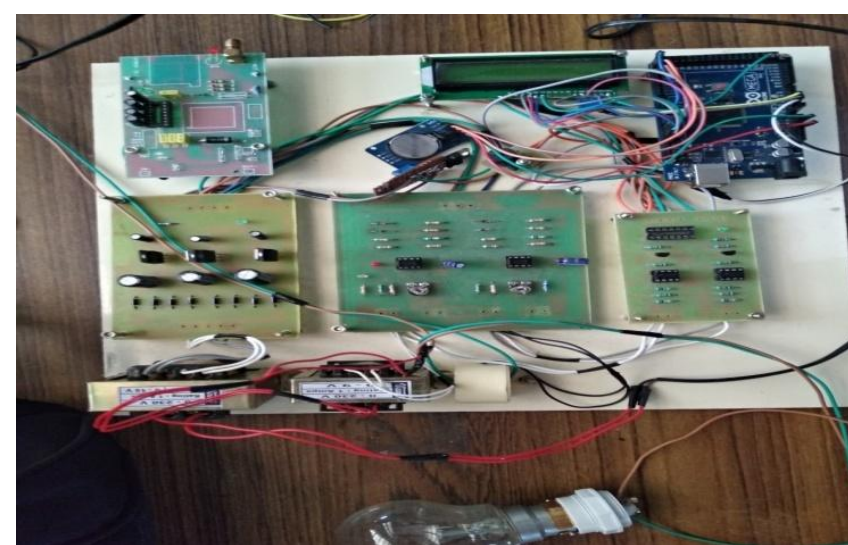

FIG -8 HARDWARE MODEL

Here lamp is used as load .when the voltage is less than $230 \mathrm{~V}$, the LCD display the message as low voltage. Where the current exceed the certain level like here we set $20 \mathrm{~mA}$ as maximum limit the LCD display the message as high current. If we use three phase induction motor as the load, as per the IEEE standards, IEEE 841 motor having model as three phase, voltage as $460 \mathrm{v}$ and $10 \mathrm{HP}$. The tolerance can be calculated and feed into micro controller for the required output.

$$
\begin{aligned}
& \text { Voltage }=460 \mathrm{~V}(\text { tolerance as } \pm 10 \%) \\
& \text { Current }=20.27 \mathrm{~A}(\text { tolerance as } \pm 10 \%)
\end{aligned}
$$

When the voltage value is less than $230 \mathrm{v}$ or equal to zero then the output would be low voltage at the same time it will intimate the workers to shut down the machine and send the message to the owner.

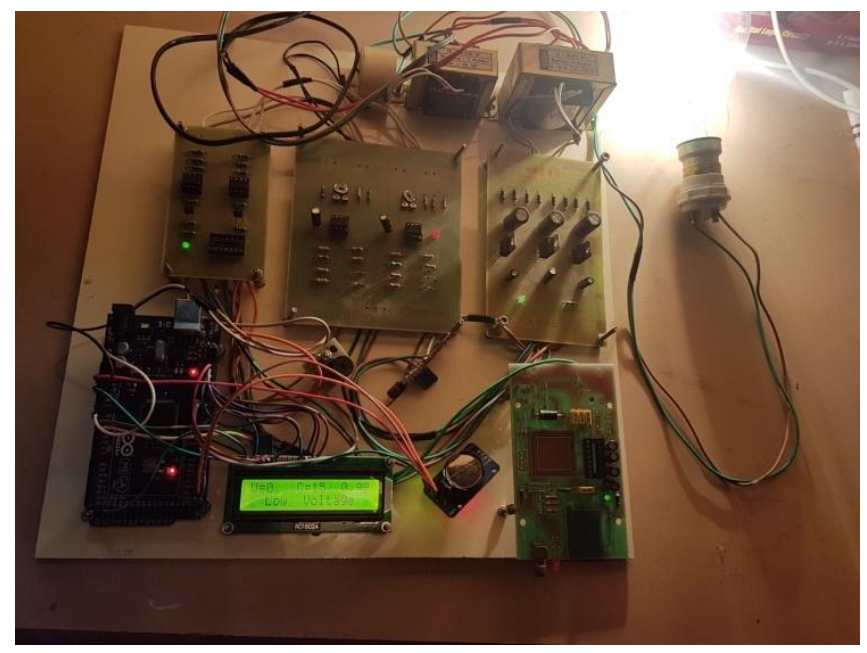

FIG -9 OUTPUT

When the current value is greater than $20 \mathrm{~mA}$ then the output would be over current at the same time it will intimate the workers to shut down the machine and send the message to the owner. 


\section{MACHINE MONITORING SYSTEM}

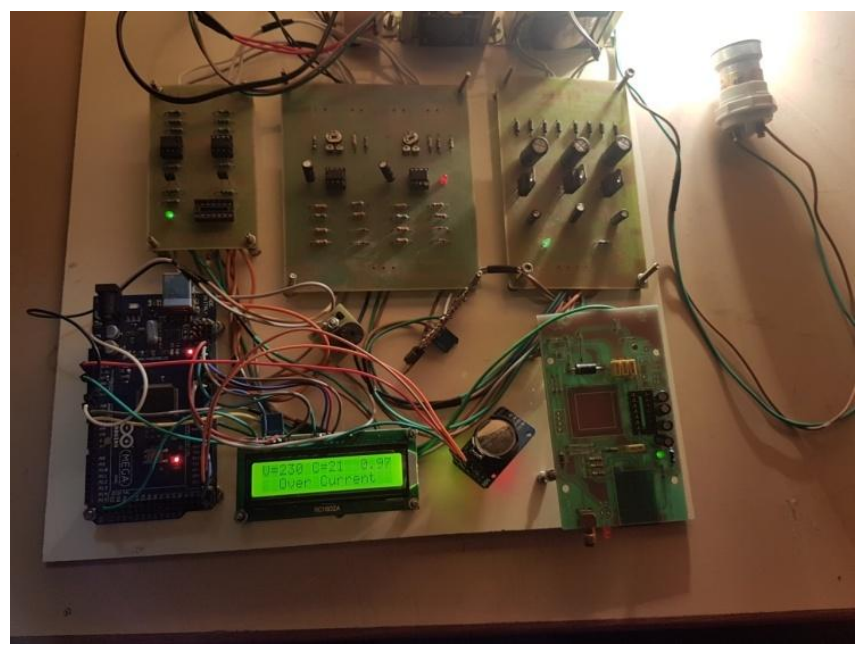

FIG -10 OUTPUT DISPLAY

\section{CONCLUSION:}

Thus the machine monitoring system has been designed to detect the fault in specified machine. Some of the advantages of machine is follows i) Continuous monitoring is possible ii) Able to satisfy the customer demand in time. In future, there is the control of machine monitoring system by wireless devices such as Wi-Fi or Bluetooth or internet enabled mobile phone. The system allow the user to control the machines individually. It can automatically turn off the main motors and turn on the motors at a specified time like if there is any fault in the machine, this machine monitoring system send the message to the owner or the manager to switch off. In that time the person can able to switch on or switch off the machine by using the mobile phone itself no need to intimate the workers to turn off it.

\section{REFERENCES}

1. A. Rubaai, A. R. Ofoli, and D. Cobbinah, "DSP-based realtime implementation of a hybrid $\mathrm{H} \infty$ adaptive fuzzy tracking controller for servo-motor drives,' IEEE Trans. Ind. Appl., vol. 43, no. 2, pp. 476-484, Mar./Apr. 2007.

2. B. S. J. Costa, P. P. Angelov, and L. A. Guedes, "Fully unsupervised fault detection and identification based on recursive density estimation and self evolving cloud-based classifier," Neuro computing, vol. 150, pp. 289-303, Feb. 2015.

3. C. Dufour, J. Mahseredjian, and J. Bélanger, "A combined state-space nodal method for the simulation of power system transients," IEEE Trans. Power Del., vol. 26, no. 2, pp. 928 935, Apr. 2011.

4. C. G. Bezerra, B. S. J. Costa, L. A. Guedes, and P. P. Angelov, "An evolving approach to unsupervised and realtime fault detection in industrial processes,' Expert Syst. Appl., vol. 63, pp. 134-144, Nov. 2016.

5. Karunamoorthy.B and Somasundaresaware.D, "Z-Source Neutral Point Clamped Inverter Fed Motor Drive" Jurnal Teknologi (Sciences \& Engineering) 76:12 PP 91-96, 2015.

6. Nagaraj, B., and P. Vijayakumar. "Evolutionary computation based controller tuning - a comparative approach." Int J Indian Pulp Paper Tech Assoc 24, no. 2 (2012): 85-90.

7. H. W. Dommel, "Digital computer solution of electromagnetic transients in single-and multiphase networks,' IEEE Trans. Power App. Syst., vol. PAS-88, no. 4, pp. 388-399, Apr. 1969.

8. H. W. Dommel, "Nonlinear and time-varying elements in digital simulation of electromagnetic transients," IEEE Trans. Power App. Syst., vol. PAS-90, no. 4, pp. 2561-2567, Nov. 1971.
9. Heffernan D., Macnamee C., Fogarty P., 2014, Runtime verification monitoring for automotive embedded systems using the ISO 26262 functional safety standard as a guide for the definition of the monitored properties, IET Software, 8 , 193-203.

10. Karunamoorthy.B and Jayasudha "Harmonics Analysis In DG system using L-Z Source Inverter", International Journal of Applied Engineering Research, Vol. 10 No.88 pp.no.95-99, 2015.

11. Enhanced Industrial Machinery Condition Monitoring Methodology Based on Novelty Detection and Multi-Modal Analysis jesus a. carino1 miguel delgado-prieto1, daniel zurita1, marta millan2, juan antonio ortega redondo1, and rene romero-troncoso 3. 